\title{
Sistemas de Controle gerencial e cultura brasileira: uma análise do modelo de Anthony
}

\author{
Ana Carolina Pimentel Duarte da Fonseca \\ Professora da Faculdade de Administração e Ciências Contábeis da Universidade \\ Federal do Rio de Janeiro - UFRJ \\ E-mail: anafonseca@pobox.com
}

\section{RESUMO}

As práticas gerenciais muitas vezes carregam valores dos pesquisadores que as desenvolveram. Dado o caráter racional e universal atribuído a determinadas práticas pela sociedade industrial, acredita-se que estão isentas de valores. No entanto, este aparente caráter racional e universal esconde valores próprios da ideologia capitalista, os quais confundem-se muitas vezes com valores da sociedade norte-americana. Analisa-se neste estudo um dos modelos mais utilizados na área de controle gerencial o modelo proposto pelo Professor Robert N. Anthony - visando explicitar os valores nele contidos e confrontá-los com os da cultura brasileira. Os resultados sugerem que algumas adaptações se fazem necessárias na sua aplicação em empresas brasileiras.

Palavras-chave: Sistemas de controle gerencial. Cultura brasileira. Cultura organizacional.

\section{Management Control systems and Brazilian culture: an analysis of Anthony's model}

\section{ABSTRACT}

Managerial practices are often based on values that are held by the researchers who developed them. Given the rational and universal character the industrial society attributes to certain practices, they are generally believed to be value free. However, this apparent rational and universal character hides values of capitalist ideology which are many times mixed with values of American society. This study analyses one of the most used theoretical structures in management control area - the model proposed by Professor Robert N. Anthony - aiming to grasp values that could be implicit in the model, in order to evaluate if they are congruent or opposite to the values present in Brazilian culture. Results suggest that some adjustments should be done when applying the model to Brazilian organizations.

Keywords: Management control, Brazilian culture, Organizational culture. 


\section{INTRODUÇÃO}

As práticas gerenciais muitas vezes carregam valores dos pesquisadores que as desenvolveram, não podendo ser aplicadas em qualquer cultura sem uma análise que aponte seus valores implícitos, ou seja, identifique seus pressupostos. (Caldas e Wood, 1998). Neste sentido, Gomes e Salas (2001) ressaltam a importância de uma análise prévia da adequação dos sistemas de controle gerencial à cultura em que a organização está inserida, na medida em que acreditam que as características do modelo adotado devem ser compatíveis não só com contexto interno da organização, mas também com seu contexto social.

Gomes e Salas (2001) apontam o plano de referência de Anthony como um dos modelos mais utilizados dentro da área de controle gerencial, tendo sido, portanto, "importado" por diversas sociedades com valores distintos da sociedade norte-americana, onde foi desenvolvido. Diante disso, parece relevante verificar se este plano está isento de valores ou se carrega valores da sociedade americana, uma vez que, como lembra Hampden-Turner e Trompenaars (1994), práticas administrativas percebidas como a única escolha econômica do sistema capitalista podem refletir valores americanos, na medida em que os valores da ideologia capitalista confundem-se com os valores da sociedade americana.

A análise das principais etapas do modelo, identificando valores implícitos nas práticas adotadas, torna mais fácil avaliar sua neutralidade como ferramenta gerencial. Portanto, o objetivo deste estudo foi analisar, do ponto de vista cultural, o modelo apresentado no livro Sistemas de Controle Gerencial por Anthony e Govindarajan (2002), daqui em diante denominado modelo de Anthony, examinando sua adequação à cultura brasileira, após explicitar os valores nele presentes.

O presente estudo foi estruturado em quatro seções. Dando prosseguimento a esta seção inicial, a segunda seção procura analisar a relação entre cultura norteamericana e as práticas que dão legitimidade às organizações, a terceira seção apresenta uma exposição das principais etapas do modelo de Anthony, procurando identificar valores e analisar se são compatíveis com os da cultura brasileira. Finalmente, 
a última seção destaca a importância do desenvolvimento de estudos que investiguem a implementação do modelo de Anthony em empresas brasileiras, buscando analisar a sua adequação aos valores presentes nas mesmas.

\section{CULTURA EMPRESARIAL, CULTURA DA RACIONALIDADE E CULTURA NORTE- AMERICANA}

Barbosa (2002) define cultura empresarial como um tipo específico de cultura dentro do capitalismo, ou seja, a cultura das organizações com fins lucrativos, que passou a identificar um determinado sistema de valores associado ao credo liberal. Assim, todas as práticas gerenciais que favorecem o empreendedorismo e a obtenção de riqueza passam a ter valor instrumental básico em relação ao desempenho ótimo de uma economia de mercado. De acordo com a autora, nas últimas décadas, a cultura empresarial foi praticamente elevada ao nível de virtudes e transformada em valores "nacionais" em quase todas as sociedades do mundo ocidental.

Segundo Hampden-Turner e Trompennars (1994), os principais valores da ideologia capitalista confundem-se com os valores da sociedade norte-americana: busca da liberdade, individualismo, propriedade privada e pragmatismo. Assim, práticas administrativas aceitas universalmente e que passaram a ser encaradas como a única escolha econômica do sistema capitalista, refletem, na realidade, valores norteamericanos.

Meyer e Rowan (1977) reconhecem que as estruturas formais de muitas organizações nas sociedades pós-industriais refletem mais o mito de seu ambiente institucional do que as demandas das suas atividades de trabalho. De acordo com os autores, as tecnologias seriam institucionalizadas e se tornariam mitos que invadiriam as organizações. Procedimentos técnicos de produção, contabilidade, seleção de pessoal ou processamento de informações, se tornariam meios consagrados de atingir os fins organizacionais. Sem levar em conta sua possível eficiência, estas técnicas institucionalizadas classificariam uma organização como apropriada, racional e moderna. Seu uso revelaria responsabilidade e evitaria acusações de negligência. Assim, o 
sucesso organizacional dependeria de outros fatores que não a coordenação eficiente e controle de atividades produtivas. Independente de sua eficiência produtiva, as organizações que incorporassem estes elementos considerados racionais em suas estruturas formais, maximizariam sua legitimidade e aumentariam seus recursos e capacidade de sobrevivência.

A análise de alguns conceitos encontrados na literatura sobre Administração aponta valores americanos, em práticas que as Escolas de Negócios sugerem que sejam adotadas em qualquer cultura. Adler e Jenilek (1986) observam que aspectos culturais norte-americanos encontram-se refletidos no próprio conceito de cultura organizacional desenvolvido nos EUA, no qual existe a crença de que a alta administração pode criar, manter e mudar a cultura das organizações e que estas organizações e seus membros encontram-se isolados do ambiente externo. Portanto, concluem não ser surpreendente que a maioria dos estudos que investigaram a influência da cultura nacional na cultura organizacional não terem sido realizados por americanos.

As teorias de motivação também parecem carregar valores americanos. Adler (1991), analisando os fatores que motivam as pessoas em culturas diferentes, conclui que não se pode assumir a universalidade da teoria de dois fatores de Herzberg, já que em cada cultura, certos fatores agem como motivadores e outros agem como fatores higiênicos. No estudo de Haire et al. (in Hofstede, 1980), pediu-se aos gerentes que avaliassem a importância das cinco necessidades da hierarquia de Maslow (fisiológicas, segurança, sociais, estima, auto- realização). Os resultados indicam que a ordenação de valores realizada pelos gerentes americanos e ingleses é a que mais se aproxima da proposta na teoria.

Da mesma forma, Bendassoli (2003, p.67) afirma que o conceito de inteligência emocional está impregnado de valores peculiares à cultura norte-americana, "como o forte desejo de ganhar e vencer, um pensamento instrumental e prático, um forte sentimento religioso (protestante), a esperança e a crença no sucesso individual, a obsessão pela quantidade e um positivismo científico".

Estes exemplos confirmam a importância de se pesquisar a extensão em que o modelo de Anthony, uma prática administrativa amplamente aceita dentro da cultura 
empresarial, reflete escolhas econômicas realizadas a partir de valores americanos, uma vez que Otley (1994) observa que a abordagem de controle gerencial de Anthony foi confeccionada em harmonia com as práticas gerenciais norte-americanas e, em menor extensão, com as britânicas, incorporando, portanto, valores pouco familiares à realidade de outras culturas.

\section{O MODELO DE ANTHONY E VALORES CULTURAIS BRASILEIROS}

Dentre os modelos de controle existentes na literatura, foi escolhido para análise o modelo de Anthony, por ser, conforme ressaltam Gomes e Salas (2001, p.37), "uma das estruturas teóricas mais utilizadas na área de controle de gestão".

A concepção abraçada por Anthony está inserida dentro da perspectiva racional do controle, cuja origem remonta à abordagem clássica de Taylor e Fayol. Conforme destacam Gomes e Salas (2001, p.32), a ênfase da perspectiva racional está no estudo dos sistemas de controle como "instrumentos explícitos e formalizados cuja implantação permite alcançar por si mesma a eficácia e a eficiência dentro da organização".

Dentro do modelo de Anthony, os objetivos e políticas são decididos em nível estratégico e são tomados como entradas para o processo de controle, que se preocupa em facilitar o alcance dos objetivos nos demais níveis hierárquicos. O sistema de controle, que visa a congruência de objetivos, enfatiza o conceito de centro de responsabilidade dentro da estrutura organizacional. O dinheiro é o denominador comum como medida de avaliação.

A seguir, são percorridas as diversas fases do processo - formulação de estratégias, orçamento operacional, avaliação de programas e remuneração dos executivos - procurando- se relacionar os valores implícitos em cada etapa aos valores da cultura brasileira.

\subsection{Formulação de estratégias}

De acordo com Anthony e Govindarajan (2002, p.92), "há um consenso de que a estratégia descreve a direção geral em que uma organização planeja mover-se para 
atingir seus objetivos". Segundo os autores, "uma empresa determina suas estratégias comparando suas capacidades fundamentais com as oportunidades de sua indústria". Conforme o esquema conceitual a que se referem, desenvolvido por Kenneth $\mathrm{R}$. Andrews, no processo de formulação da estratégia a alta administração avalia os pontos fracos e fortes da empresa à luz das oportunidades e dos riscos que o ambiente apresenta, estabelecendo estratégias que levem em conta estes aspectos. Os autores acrescentam, ainda, que em empresas diversificadas cabe à alta administração distribuir recursos entre suas unidades, decidindo se os recursos financeiros gerados por algumas unidades serão utilizados para financiar outras.

No processo descrito acima, em que a alta administração desenha estratégias que serão implementadas por seus subordinados, existe uma tendência de se ignorar certas particularidades do mundo real, pois, além de só serem enxergados os fenômenos que já constam de um determinado referencial teórico, supõe-se que os conceitos universais sejam capazes de organizar a realidade. (Hampden-Turner e Trompenaars, 1994, p.27).

De acordo com Hampden-Turner e Trompenaars (1994, p. 21), dos países por eles estudados, os EUA se destacam como o país mais universalista. Nenhuma outra cultura é tão eficiente em elaborar regras para as pessoas seguirem. Entretanto, esta tendência não parece consistente com a observação de Damatta (2000, p.25), de que "o segredo de uma interpretação correta do Brasil jaz na possibilidade de estudar aquilo que está 'entre' as coisas". Prosseguindo, o autor acrescenta:

O ponto é utilizar consistentemente a descoberta de que a sociedade brasileira é relacional. Um sistema onde o básico, o valor fundamental é relacionar, juntar, confundir, conciliar. Ficar no meio, descobrir a mediação e estabelecer a gradação, incluir (jamais excluir). Sintetizar modelos e posições parece constituir um aspecto central da ideologia dominante brasileira. (Damatta, 2000, p.108).

O texto acima sugere uma capacidade de captar as conexões particularistas e os aspectos holísticos dos problemas, em oposição ao universalismo presente na cultura norte-americana. Não parece, portanto, coincidência o fato de que Tanure (2005) tenha destacado como traço cultural brasileiro a flexibilidade, que seria, segundo a autora, uma forma de operar aparentes paradoxos, conviver com opostos. Corroborando as 
conclusões de Tanure, Hilal e Hofstede (2003) destacam que, em geral, a cultura brasileira é considerada flexível e adaptável, aparentemente menos voltada para os extremos e favorecendo soluções que destacam a harmonia em vez do conflito aberto. $\mathrm{Na}$ concepção de Trompenaars (1995), trata-se de uma cultura particularista que, ao contrário de uma cultura universalista, não aplica regras gerais para todos, mas submeteas ao crivo das relações pessoais e às peculiaridades de cada situação.

A formulação de estratégias também envolve a questão de controle sobre transformações. Adler e Jelinek (1986) ressaltam que os americanos, por acreditarem que têm influência sobre o ambiente, planejam seu trabalho, decidindo o que completarão e quando. Por outro lado, alguns estudos apontam uma tendência ao fatalismo na cultura brasileira. A análise de conteúdo realizada por Rocha e Rocha (1993) em anúncios de seguros em revistas brasileiras e americanas, constata uma ideia de maior controle sobre o futuro nos anúncios americanos em comparação com os brasileiros. Na amostra analisada, não foi encontrada a palavra controle, o que indicaria uma atitude mais fatalista. Neste sentido, Amado e Brasil (1991) afirmam que, do ponto de vista do capitalismo puritano transplantado para o Brasil, no pensamento anglo-saxônico, trabalho não significa hoje, mas o futuro. Este ponto de vista entra em conflito com a realidade brasileira onde, segundo eles, as pessoas vivem de uma maneira fatalista e acreditam em líderes carismáticos e soluções mágicas. Esta posição parece coerente com o espírito de aventura descrito por Holanda (1984, p.13), na medida em que em ambos se percebe uma crença no poder do destino, da sorte e, portanto, de falta de controle. De acordo com o autor, o espírito de aventura presente em nossa cultura contrasta com a ética do trabalhador. Enquanto o primeiro tem como ideal "colher o fruto sem plantar a árvore", o trabalhador, ao contrário, "é aquele que enxerga primeiro a dificuldade a vencer, não o triunfo a alcançar".

No que se refere à distribuição de recursos entre as unidades, Hampden-Turner e Trompenaars (1994) observam que o pensamento americano de que todos devem ter oportunidades iguais, aliado a idéia de vencer, faz com que os negócios sejam encarados como um jogo, sendo o sucesso econômico o resultado de uma série de competições entre firmas, em que os números indicam mensalmente quem está vencendo. Por esta 
razão, as firmas britânicas e norte-americanas frequentemente estabelecem "mercados internos" dentro das corporações em que os centros de lucro competem por recursos. Barbosa (1992, p.15) observa que a igualdade, como valor, não possui o mesmo significado na sociedade brasileira e na norte-americana. Nos EUA ela se apresenta como um direito e pode resultar em desigualdade, pois "um melhor desempenho por parte do indivíduo ou de um grupo os intitula a uma posição diferenciada em relação aos demais" No Brasil invoca-se também uma igualdade moral que tem origem na idéia de unidade biológica do ser humano. Nas palavras da autora:

\begin{abstract}
Parece-me, que é devido justamente a esta concepção dupla da igualdade, como um direito e como um fato, que se torna possível na sociedade brasileira se ultrapassar o tratamento postulado pelo sistema de leis universalizantes e, portanto, igualitárias, com argumentos também vinculados a essa mesma vertente, porém fundados numa equivalência moral, como é o caso do jeitinho (Barbosa, 1992, p.117).
\end{abstract}

Diante da ponderação acima, é provável que, nas organizações brasileiras a distribuição de recursos entre unidades não funcione como uma disputa em que os mais capazes receberão mais recursos. Nesta repartição outros fatores poderão ser levados em consideração, apontando na direção de uma igualdade de ordem moral.

\title{
3.2 Orçamento operacional
}

Anthony e Govindarajan (2002) definem orçamento operacional como um plano da organização para um período específico, geralmente para um ano. Os principais aspectos envolvidos neste processo, segundo os autores, são:

O orçamento apresenta uma estrita coordenação com o plano estratégico, usando informações mais atuais. As receitas e as despesas são realinhadas para corresponderem a centros de responsabilidade e não a programas; dessa forma, o orçamento mostra as despesas que se espera que sejam incorridas por cada executivo. A preparação do orçamento é essencialmente um processo de negociação entre cada gerente de centro de responsabilidade e seu superior hierárquico. O resultado das negociações é uma definição de consenso a respeito das despesas a serem realizadas durante $o$ ano (no caso de centros de responsabilidade que são centros de despesas), ou do lucro previsto ou do retorno do investimento (no caso de centros de responsabilidade que são centros de lucro ou centros de investimento) (Anthony e Govindarajan, 2002, p.45). 
No processo de negociação entre as partes, podem ser encontrados alguns valores da sociedade norte-americana. Hofstede (1980) observa que a administração por objetivos pressupõe que os subordinados sejam suficientemente independentes para negociar significativamente com o chefe, o que ocorreria nos EUA, que apresentam baixos índices de distância do poder, ou seja, os membros menos poderosos das instituições e organizações não aceitam com facilidade que o poder fique distribuído desigualmente.

Duas outras características da cultura norte-americana contribuem para acentuar este aspecto: a orientação interna e o forte individualismo. A primeira faz com que as conviç̧ões internas dos indivíduos sejam a origem dos objetivos e direção da organização. A segunda, por sua vez, significa que os gerentes consideram o indivíduo a peça básica da organização e responsável por todo o seu sucesso. Acredita-se que as pessoas devem "pensar por si mesmas" e "fazer as suas coisas", ao invés de se deixarem influenciar por outras pessoas ou pelo curso dos eventos externos. O indivíduo autodeterminado, perseguindo tenazmente o seu sonho pessoal, é o retrato do alto grau de empreendedorismo presente na sociedade americana, (Hampden-turner e Trompenaars, 1995, p. 63). Este indivíduo autodeterminado não só será responsável por seus atos, bem como defenderá seus pontos de vista. Estes aspectos nem sempre são encontrados em outras culturas, nas quais preservar a harmonia pode ser mais importante do que confrontar diretamente a outra pessoa para defender um ponto de vista. (Stephens e Geer, 1995 e Kelley et al.1987).

A sociedade brasileira é uma sociedade hierárquica em que as relações pessoais são muito importantes, conforme conclui Motta (1997, p.31):

\begin{abstract}
A base da cultura brasileira é o engenho, é o binômio casa grande e senzala. $O$ senhor de engenho era um senhor absoluto em seus domínios. Cabia a ele administrar suas terras, sua família e seus escravos. A distância social era contrapartida da proximidade física.
\end{abstract}

Este aparente paradoxo é explicado por DaMatta (2000, p.108), ao observar que, enquanto nos EUA o sujeito do sistema é o indivíduo, aqui é também a "relação, o elo, o ponto de ligação", o que permite que, ao contrário dos EUA, onde "há exclusão e 
separação", haja "junção e hierarquização. "

Assim, segundo Prates e Barros (1997, p.60), a combinação da concentração do poder e do personalismo (atração pessoal), que resulta no paternalismo, traria algumas consequências para o processo de negociação dentro das organizações. Em primeiro lugar, é importante considerar as relações de amizade entre as partes, pois não se consegue separar os negócios das relações pessoais. Em função deste sistema de relações pessoais, busca-se evitar o conflito de ideias para preservar a harmonia, comportamento que seria acentuado pela postura de espectador apontada por Prates e Barros (1997, p.61), a qual, por sua vez, seria consequência da presença de um poder externo dominante que limitaria nossa "consciência crítica" e resultaria em "baixa iniciativa", "pouca capacidade de realização por autodeterminação" e "transferência de responsabilidade das dificuldades para as lideranças". Reforçando este traço, destaca-se o medo de errar que é, segundo Tanure (2005, p.108), "a contraparte do paternalismo" e que levaria ao "desejo de acertar sempre e assim ser reconhecido pelo grande poder", o que, segundo a autora, pode ser "paralisante".

\subsection{Avaliação de programas}

Em relação ao processo de avaliação, Anthony e Govindarajan (2002) afirmam:

O processo de avaliação é a comparação dos valores reais com os valores que deveriam ter sido incorridos nas circunstâncias. A menos que as circunstâncias tenham mudado daquelas assumidas no processo de orçamento, a comparação deve ser feita entre os valores orçados e os valores reais. Se as circunstâncias mudaram, as mudanças são levadas em consideração na análise. A análise deve levar a uma crítica de louvor ou construtiva dos executivos do centro de responsabilidade. (Anthony e Govindarajan, 2002, p.45).

Verifica-se, portanto, que a avaliação tem por base o desempenho do empregado, ou seja, o status alcançado, um forte traço cultural da formação dos Estados Unidos, que se contrapõe ao status atribuído. Para Schneider (1988, p.11), quando a avaliação é feita com base na realização, admite-se que "a performance, isto é, o que foi feito ou realizado é importante e pode ser medido objetivamente. O que é avaliado é então, comportamento e, não, características". Por outro lado, acrescenta a autora que, quando o que conta é o 
status atribuído, como ocorre nas firmas japonesas, "existe uma maior preocupação em julgar a integridade, a conduta moral, a lealdade e o espírito cooperativo de uma pessoa do que em alcançar um alto volume de vendas".

A avaliação com base no desempenho, a meritocracia, não tem sido a forma mais usada nas empresas brasileiras, porque não atende à nossa concepção de igualdade moral:

No Brasil, o grupo todo se move em conjunto a partir do critério de antiguidade ou senioridade, que é o único valor a vazar a nossa ótica igualitária e a introduzir gradações, ou ninguém se move isoladamente pelo desempenho pessoal. [...] $\mathrm{O}$ critério de antiguidade é algo que está ao alcance de todos e pode ser estendido, indiscriminadamente, a todas as categorias. Já o desempenho (mérito) depende dos indivíduos, de suas especificidades, enquanto 'personalidades e caracteres', e nem todos podem tê-lo ou consegui-lo (Barbosa,1992, p.118-119).

Outra questão envolvida no processo de avaliação é a mensuração de resultados. Segundo Schneider (1989), as organizações que demonstram preferência por números e por evidência estatística em detrimento de exemplos descritivos, acreditam que fatos e números reduzam incertezas, sendo a verdade e a realidade determinadas pelo que é mensurável e tangível. A informação qualitativa que tende a ser mais ambígua e de difícil mensuração é, assim, ignorada. Sobre esse aspecto, Hofstede (1991) ressalta que, nos países individualistas, as informações fornecidas pelos sistemas de contabilidade tendem a ser encaradas com muito mais seriedade e consideradas como mais indispensáveis do que nos países coletivistas. Nestes últimos, as pessoas estão integradas em grupos coesos que protegem seus componentes em troca de lealdade inquestionável, havendo, portanto, outros meios mais sutis de informação sobre a saúde das organizações e o rendimento de seus membros, do que a informação explícita contida nos serviços e relatórios da contabilidade. Comparando os mecanismos de controle das empresas americanas e japonesas, Rocha (2000) ilustra este aspecto: 
Os mecanismos de controle também diferenciam empresas japonesas e americanas. Na empresa americana, estes mecanismos são explícitos, no sentido de serem verbais e formalizados. Tudo é medido, como preconizava Weber. Como nem tudo, porém, pode ser medido, há coisas importantes que escapam aos sistemas de controle. Ganha-se, porém, ao explicitar parâmetros de avaliação e controle, que servem como indicadores e balizadores- ainda que imperfeitospara os empregados. Na organização japonesa, ao contrário, os controles tendem a ser implícitos, informais e subjetivos (Rocha, 2000, p.108)

Outros fatores contribuem para incentivar a preferência por números nos EUA. Hampden- Turner e Trompenaars (1995) acreditam que o universalismo também estimule o estabelecimento de medidas quantitativas na sociedade americana. Segundo eles, são inúmeros os exemplos de práticas administrativas nas quais existe uma simplificação da realidade, de preferência numérica, em que se julga a abstração superior à realidade a partir da qual foi feita.

Outro aspecto que também estimularia o uso de medidas quantitativas seria a preferência pela análise. A prática de reduzir e analisar as empresas através de índices de lucratividade no curto prazo adquiriu total legitimidade no contexto norte-americano, onde o foco é sobre os átomos resultantes da análise. Entretanto, esta tendência à análise pode levar à dificuldades na hora de juntar as partes novamente, perdendo-se a noção do todo, ou, ainda, a decisões erradas, uma vez que a ênfase em um índice de lucratividade pode comprometer a posição competitiva da empresa no futuro. (Hampdenturner e Trompenaars, 1995). Os resultados do estudo de Harrison et al. (1994) confirmaram a hipótese por eles levantada de que o uso de técnicas quantitativas no processo de planejamento e controle seja mais intenso nas sociedades onde predomina 0 pensamento analítico, do que nas sociedades em que o pensamento sintético é prevalecente.

Finalmente, a ênfase quantitativa também é decorrente da visão norte-americana de que o tempo é fortemente sequencial, ou seja, cada coisa deve ser feita de uma vez, de forma linear. Os Estados Unidos são símbolo das culturas onde "tempo é dinheiro", onde tempo é um bem econômico, um recurso escasso, para o qual deve ser encontrada uma alocação ótima (Usunier, 1991, p.199). Nesta visão, o tempo pode ser poupado, gasto, desperdiçado ou até mesmo comprado. Isto explica o fato de os EUA terem sido a 
primeira cultura de negócios a estimular o alcance de tempos-padrão cada vez menores, com máquinas e linhas de montagem cada vez mais rápidas. Ao racionalizar a corporação de forma sequencial, as pessoas são vistas como custos e despesas (Hampden-turner e Trompenaars, 1995, p.74-75).

As características da sociedade brasileira não parecem proporcionar um ambiente adequado ao uso de medidas quantitativas. A facilidade de lidar com a ambiguidade e sintetizar, descrita por Damatta, sugere uma capacidade de lidar com informações pouco precisas e de extrair do contexto aspectos não contemplados nas medidas contábeis. Por outro lado, a característica relacional da sociedade brasileira determina, conforme proposto por Hall (1994), uma ênfase nas pessoas em detrimento das tarefas, abrindo espaço para a realização de várias tarefas simultaneamente, o que não parece consistente com a racionalização da organização de forma sequencial, em que as pessoas são vistas como custos e despesas.

Outra observação que pode ser feita a respeito da avaliação dentro do referencial de Anthony é que ela é individual. Ueno e Sekaran (1992) relatam que os resultados de um estudo que comparou práticas contábeis entre os Estados Unidos e Japão mostraram que companhias norte-americanas davam mais importância ao uso de dados contábeis para avaliação individual dos gerentes do que as companhias japonesas. Além disso, na visão de Hampden- Turner e Trompenaars (1995, p.28), a preferência por decisões individuais na cultura americana pode ser explicada com base na tendência universalista apresentada por essa cultura. A dificuldade em lidar com a participação existe porque ela demanda conexões particularistas. A participação só é válida se o chefe se encontra preparado para mudar de ideia em função das sugestões recebidas, o que implica que a solução não deve seguir uma receita pré-determinada. Fica difícil ter "boas relações humanas" se uma das partes acredita ter explicações universais para a relação, as quais controla unilateralmente.

Neste sentido, Rocha (2000, p.94) compara o modelo ideal do gerente americano, onde a decisão é vista como responsabilidade solitária do mesmo, aos mitos individualistas do Oeste americano, nos quais o cowboy encarnava "o indivíduo atlético, corajoso, apto a cuidar de si, capaz de múltiplos expedientes: um especialista em 
sobrevivência em ambiente hostil".

Dibella (1993), em seu estudo, verificou que as suposições norte-americanas sobre avaliação de performance contrastam com as dos ugandenses. A crença dos americanos é de que a responsabilidade se tornava muito difusa quando cobrada de um grupo. Para eles, era mais efetivo tornar os indivíduos responsáveis de modo que a gerência possa responsabilizá-los em caso de falha. Por outro lado, os ugandenses trabalham sob a suposição de que grupos são mais seguros do que indivíduos. Em seu pensamento, ao trabalhar juntos, os indivíduos podem tomar conta uns dos outros. Além disso, seria inapropriado responsabilizar um indivíduo por falha em sua performance, já que o destino, ao invés da competência, determina os resultados.

A preferência por decisões individuais dentro do modelo de Anthony também não parece adequada à cultura brasileira, onde a ênfase nas relações pessoais convida à participação de todos na discussão dos assuntos. No entanto, a participação não envolve necessariamente atribuição de responsabilidade aos indivíduos, pois existe um alto grau de paternalismo na sociedade brasileira que resulta na postura de espectador (transferência de responsabilidade por parte dos subordinados para as lideranças) e no medo de errar.

Fonseca (1997), sintetizando alguns depoimentos de brasileiros sobre tomada de decisão dentro do sistema de planejamento e controle, aponta na mesma direção:

\begin{abstract}
Dentro do grupo brasileiro estudado, o medo de arriscar e de arcar com a responsabilidade da decisão acaba induzindo a uma busca por consenso, a qual favorece as decisões em grupo. Os informantes declararam que gostam que o chefe peça a sua opinião e se sentem motivados com isso. Entretanto, quando os problemas tomam maiores proporções, os chefes são envolvidos na tomada de decisão pois os indivíduos preferem não fazer nada com medo de perder os seus empregos, evitando tomar a decisão. [...] Assim, de um modo geral, parece que no Brasil todos gostam de participar das decisões, mas a tomada de decisão deve ser do chefe (Fonseca, 1997, p.237).
\end{abstract}

Finalmente, Anthony e Govindarajan (2002) destacam a importância do feedback dentro do sistema de avaliação de performance: 
Os indivíduos ficam profundamente motivados quando recebem relatórios a respeito do seu próprio desempenho. Sem essa retro-alimentação, as pessoas têm dificuldade para sentir terem cumprido uma tarefa e para sentirem-se realizadas; têm também certa dificuldade para definir ações corretivas necessárias para atingir seus objetivos (Anthony e Govindarajan 2002, p.614).

Conforme ressalta Lewis (1996, p.79), os americanos "precisam de feedback constante, encorajamento e elogios do seu executivo sênior". Entretanto, para Schneider (1988), esta necessidade não é sentida igualmente por todas as culturas. A autora argumenta que se assume que o feedback dado será usado para corrigir ou melhorar a performance passada, o que requer que os indivíduos que recebem o feedback desejem se auto-avaliar ao invés de culpar outros ou condições externas pela sua performance. Segundo a autora, o próprio ato de dar feedback direto não leva em conta a idéia de harmonia (saving face), tão crucial nas culturas orientais, onde confrontar um empregado discutindo fracasso de uma maneira direta e aberta seria considerado de muito pouco tato.

A cultura brasileira parece se enquadrar nos dois casos acima. Em primeiro lugar, a eficácia do feedback pode ser reduzida em função da tendência de culpar outros ou condições externas pelo fracasso, descrita anteriormente (fatalismo). Em segundo lugar, como as relações pessoais misturam-se com as de trabalho, qualquer crítica ao trabalho é levada para o campo pessoal. Segundo Trompenaars (1995, p.74), este comportamento é comum nas culturas difusas, em que não há separação entre os diversos espaços da vida, e do momento que alguém é admitido em um deles, acaba entrando em todos os outros. Este aspecto, aliado a uma alta distância do poder, resulta numa necessidade de evitar conflitos, principalmente no, sentido liderado-líder, conforme apontado por Tanure (2005, p.107). Ilustra bem este fato a declaração feita por um funcionário da subsidiária brasileira de uma multinacional, em pesquisa realizada por Fonseca (1997, p.189), de que o feedback tende a ser "construtivo para a empresa, mas destrutivo para a minha pessoa".

\subsection{Remuneração dos executivos}

Segundo Anthony e Govindarajan (2002, p.613), "a concessão de incentivos é um 
mecanismo importante para encorajar e motivar executivos a atingirem os objetivos da organização". Além disso, os autores acrescentam:

\begin{abstract}
Os indivíduos tendem a ser motivados mais fortemente pela possibilidade de ganharem prêmios de incentivo do que por receio de punição, fato que sugere que os sistemas de controle gerencial devem ser orientados para incentivos de prêmios. A motivação é mais fraca quando a pessoa considera um incentivo inatingível, ou, ao contrário, atingível com demasiada facilidade. Ela é forte quando o objetivo pode ser atingido com algum esforço e quando a pessoa considera sua obtenção importante para a satisfação de seus desejos (Anthony e Govindarajan 2002, p.614).
\end{abstract}

Estas afirmações sugerem que os indivíduos se sentem motivados por desafios e esperam ser recompensados ao atingirem os objetivos traçados. A motivação implícita seria por realização a qual, na abordagem de Hofstede (1991, p.124), pressupõe duas escolhas culturais - uma vontade de aceitar riscos pouco familiares (equivalente à baixa fuga à incerteza, existente em sociedades que se sentem pouco ameaçadas por situações incertas ou desconhecidas) e uma preocupação com performance (equivalente à forte masculinidade, observada em sociedades que dão mais valor ao sucesso material do que à qualidade de vida). Segundo o autor, esta combinação é encontrada exclusivamente em países do grupo anglo-americano e em algumas das suas antigas colônias. Isto talvez explique porque a palavra achievement (realização) é dificilmente traduzível em outra língua que não seja o inglês.

Observando experimentos realizados com belgas e americanos, nos quais os americanos se esforçavam para vencer e os belgas, com menor tolerância à incerteza, evitavam perder, Hofstede (1980) conclui que a fonte de motivação em sociedades com alta fuga à incerteza seria medo de falhar, ao passo que, em culturas com baixa fuga à incerteza, seria esperança de sucesso. Por outro lado, Hofstede (1991, p.94) destaca ainda que, enquanto as culturas masculinas ficam motivadas com o enriquecimento das tarefas, as culturas femininas preferem oportunidades para ajuda mútua e contatos sociais na realização das mesmas.

Para Currie (1991), as práticas de compensação correntes, ligadas à performance, contém, na realidade, um elemento de risco, como, por exemplo, esquemas envolvendo 
compensação diferida, recompensas relacionadas com performance e opções por ações. Em culturas que toleram a incerteza, como Hong Kong, Suécia e Grã-Bretanha, esquemas de incentivo deste tipo são prontamente aceitos. Em culturas tais como Alemanha, Espanha e França, entretanto, eles são, com frequência, profundamente impopulares e podem ser desmotivadoras como ilustrado no exemplo que segue:

Na subsidiária alemã, o obstáculo era a forte fuga à incerteza daquele país. Todos os executivos se recusaram a participar porque eles consideravam os resultados do esquema como flexíveis demais. Não havia garantias, nenhuma estrutura através da qual um indivíduo pudesse calcular os riscos envolvidos e nenhuma maneira de relacionar performance a algum tipo de resultado previsível. Como resultado, os executivos o consideravam menos como uma compensação do que como um jogo (Currie, 1991, p.11).

Apesar da constatação de Tanure $(2005$, p.73) de que o índice de Fuga à Incerteza sofreu uma queda na cultura brasileira, o medo de falhar encontrado por Hofstede (1980) parece coerente com o medo de errar mencionado pela autora em relação à cultura brasileira, o qual seria decorrente do grau de paternalismo presente na mesma. As práticas de compensação presentes indicam a preferência por compensações para diluir o risco e fazer justiça social. De acordo com Barbosa (1999, p.71), o único valor legítimo na perspectiva igualitária radical é a senioridade, pois é "um atributo ao alcance de todos, porquanto só depende da simples permanência no emprego", enquanto o mérito, "depende do indivíduo e de suas especificidades, nem todos o possuem ou podem alcançá-lo". Nas palavras da autora:

\begin{abstract}
O esforço de cada um, a vontade de realizar (achievement) e as diferenças de talento naturais não funcionam como vetores que transformam indivíduos comuns em winners, como na sociedade norte-americana, mas como expressões "objetivadas" de processos históricos e sociais sobre os quais os indivíduos têm pouco controle. Como os indivíduos nascem em posições sociais distintas, eles desenvolvem habilidades desiguais. Elas não são naturais, no sentido de inatas. Portanto, os resultados positivos e negativos advindos das habilidades e talentos de cada um não são responsabilidade do indivíduo, e sim de todo corpo social. Daí a lógica distributiva que subjaz à concepção de igualdade substantiva brasileira. (Barbosa, 1999, p.65-66).
\end{abstract}

Reforçando a postura acima, Tanure (2005, p.83) observa ainda que, com relação à preocupação com performance, presente nas culturas masculinas, na sociedade 
brasileira a busca de oportunidades de crescimento para atingir cargos mais altos é atenuada pela ênfase nas relações pessoais e pela importância de um ambiente amigável e cordial entre pessoas, resultando numa posição intermediária com relação a este índice.

Em sua pesquisa a respeito de informações contábeis relativas a planos de incentivos a funcionários em companhias abertas, Nunes (2004) observa que foi encontrado um reduzido volume de companhias que possuem planos atrelados a ações e opções de ações dentro de seus incentivos e que também é reduzido o montante de funcionários que participam destes programas, geralmente restrito aos níveis de altagerência e diretoria executiva. Da mesma forma, Fernandes (2005), analisando casos de implantação do Balanced Scorecard em empresas brasileiras, verificou que as organizações vinculavam as recompensas aos grupos embora não as estabelecessem em nível individual.

\section{CONSIDERAÇÕES FINAIS}

Os resultados da análise das diversas fases do modelo de Anthony apontam uma correspondência entre suas práticas e os valores da cultura norte-americana, correspondência essa que não se observa para os valores da cultura brasileira. Portanto, a atenção dada às diferenças entre as culturas brasileira e norte-americana parece condicionar o sucesso da implantação do modelo.

Dada a intensa utilização desta abordagem em empresas brasileiras e a extensão em que é ensinada nas Escolas de Administração, cabe aos pesquisadores da área avaliarem os pontos ressaltados em cada etapa do modelo, onde é provável que ocorram respostas diferentes daquelas que seriam dadas por pessoas que abraçassem valores norte-americanos. Como os contextos das organizações de negócios americanas e brasileiras não são semelhantes, práticas são introduzidas em contextos diferentes daqueles onde tiveram origem, resultando em atividades que se mostram inapropriadas para situações específicas. 
Os resultados da pesquisa de Canclini (2003, p.115) sugerem que a "traduzibilidade" entre as culturas é limitada", mas "não é impossível". Segundo o autor, "a diferença não se manifesta como compartimentalização de culturas isoladas, e sim como interlocução com aqueles com que estamos em conflito ou buscamos alianças". Os resultados de sua pesquisa indicam que existem "possibilidades de convivência", [...] "de compartilhar recursos materiais e simbólicos", [...] "não de dissolver diferenças, mas de torná-las combináveis".

Assim, somente após os valores contidos nas práticas gerenciais serem explicitados e confrontados com a realidade onde as práticas serão aplicadas, é que as diferenças poderão se tornar combináveis, mediante a adaptação de alguns aspectos e/ou alteração de outros Neste ponto, torna-se fundamental a escolha da metodologia de pesquisa.

Conforme alerta Chanlat (1996, p.32), algumas dimensões do ser humano ficaram esquecidas em função da concepção instrumentalista dominante. Cabe, portanto, tentar resgatar a subjetividade e a afetividade dos "objetos de pesquisa" através de abordagens que permitam aos pesquisadores "interpretar o sentido que as pessoas dão aos seus gestos, às suas ações e aos seus sentimentos". Uma forma de chegar a tais resultados seria a realização de estudos etnográficos que permitissem "escapar do (s) discurso (s) dominante (s) e, assim, reconhecer a realidade dos praticantes e das empresas que atuam no Brasil" (Faria, 2003, p.20). Estes estudos buscariam escutar a voz dos informantes, no caso, as pessoas que utilizam, no seu dia-a-dia, o modelo examinado.

\section{REFERÊNCIAS}

ADLER, N.J. 1991. International dimensions of organizational behaviour. Califórnia, Wadworth Publishing Com pany, 314 p.

ADLER, N.J. e JELI NEK, M. 1986. Is 'organization culture' culture bound? Human Resource Management, 25(1): 73- 90.

Amado, G. e Brasil, H.V. 1991. Organizational behaviors and cultural context: the Brazilian "jeitinho". International Studies of Management and Organization, 21(3): 38- 61. 
ANTHONY, R.N. e GOVI NDARAJAN, V. 2002. Sistemas de controle gerencial. Tradução Adalberto Ferreira das Neves. São Paulo, Atlas, 1024 p.

BARBOSA, L. 2002. Culturas e empresas. Rio de Janeiro, ed. Jorge Zahar, 58p.

1999. Igualdade e meritocracia: a ética do desempenho nas sociedades modernas. Rio de Janeiro, Ed. Fundação Getúlio Vargas, 216 p.

1992. O jeitinho brasileiro. $4^{\mathrm{a}}$ ed. Rio de Janeiro, Campus, 158 p.

BENDASSOLI, P.F. 2003. Afeto sob controle. Revista de Administração de Empresas Executivo, 2 (2): p.63- 67.

CALDAS, M. e WOOD, T. 1998. Antropofagia organizacional. In: Encontro Anual da Associação Nacional dos Programas de Pós-Graduação em Administração, 22. Foz do Iguaçu, 1998. Anais Eletrônicos Foz do Iguaçu, ANPAD, 1CD. p.1-14.

CANCLINI , N. G. 2003. A Globalização Imaginada. Tradução Sérgio Molina. São Paulo, Editora I luminuras, $224 \mathrm{p}$.

CHANLAT, J.F. 1996. Por um a antropologia da condição humana nas organizações. In: $\quad$ O indivíduo na organização - dimensões esquecidas, $3^{a}$ ed., São Paulo, Atlas, 208 p.

Currie, R. 1991. Remuneration to fit the culture. Multinational Business, (3) p. 8- 17.

DAMATTA, R. 2000. A casa e a rua: espaço, cidadania, mulher e morte no Brasil. 6aㅡ ed., Rio de Janeiro, Rocco, 164 p.

Dibella, A.J. 1993. The role of assumptions in implementing management practices across cultural boundaries. The Journal of Applied Behavioural Science, 29 (3): p.311327.

FARI A, A. 2003. Pesquisa em redes estratégicas: descobertas e reflexões etnográficas. Revista de Administração de Empresas, 43 (1): p.11- 23.

FERNANDES, F.P.P. 2005. Implantação do Balanced Scorecard em empresas brasileiras sob a perspectiva da cultura nacional. Rio de Janeiro, RJ. Dissertação de Mestrado em Ciências Contábeis. Faculdade de Administração e Ciências Contábeis. Universidade Federal do Rio de Janeiro, 104 p.

FONSECA, A.C.P.D. 1997. Percepções de incerteza em um sistema de planejamento e controle: um estudo comparativo Brasil-Inglaterra. Rio de Janeiro, RJ. Tese de Doutorado em Administração. Instituto COPPEAD de Administração. Universidade 
Federal do Rio de Janeiro, 317p.

GOMES, J.S. e SALAS, J. M.A. 2001. Controle de gestão: uma abordagem contextual e organizacional. 3aㅡ ed. São Paulo, Atlas, 192 p.

HALL, E.T. 1994. Monochronic and polychronic time. In: PORTER, R.E; SAMOVAR, L.A. Intercultural Communication. Califórnia, Wadworth Publishing Company, p. 264- 271.

HAMPDEN- HAMPDEN- TURNER, C. e TROMPENAARS, F. 1994. The seven cultures of capitalism. London, Piatkus, $420 \mathrm{p}$.

Harrison, G.L. et al. 1994. The influence of culture on organization design and planning and control in Australia and United States compared with Singapore and Hong Kong. Journal of International Financial Management and Accounting, 5(3): p.242- 261

HI LAL, A. e HOFSTEDE, G. 2003. Organizational culture dimensions: findings from a brazilian company In:Workshop em Interacionalização de Empresas, I V, 2003. Rio de Janeiro. Anais...Rio de Janeiro, COPPEAD, 1 CD, p.1- 60.

HOFSTEDE, G. 1991. Cultures and organizations: the software of the mind. London, McGraw Hill, 290 p.

1980.Culture's consequences: international differences in work-related values. Beverly Hills, Sage Publications, 329 p.

HOLANDA, S.B. 1984. Trabalho \& aventura. In_. Raízes do Brasil. Rio de Janeiro, J Olympio, p.12- 40.

Kelley, L. Whatley, A. e Worthley, R. 1987. Assessing the effects of culture on managerial attitudes: a three- culture test. Journal of International Business Studies, p.17- 31.

LEWI S, R.D. 1986. When cultures collide. London, Nicholas Brealey Publishing, 334 p.

MEYER, J.W. e ROWAN, B. 1977. Institutionalized Organizations: form al structure as myth and ceremony. American Journal of Sociology, 83(2): p. 340-363.

MOTTA, F.C. P. 1997. Cultura e Organizações no Brasil. In:_e CALDAS, M.P. (Orgs). Cultura organizacional e cultura brasileira. São Paulo, Atlas, p.25- 37.

NUNES, A.A. 2004. Práticas Contábeis utilizadas pelas companhias abertas brasileiras no reconhecimento e divulgação em seus relatórios anuais, de informações relativas a planos de incentivos a funcionários, associados à cessão de ações e opções de ações. Rio de Janeiro. Dissertação de Mestrado.. Faculdade de Administração e Ciências 
Contábeis. Universidade Federal do Rio de Janeiro, 303 p.

OTLEY, D. 1994. Management control in contemporary organization: towards a wider framework. Management Accounting Research, v. 5.

PRATES, M. A.S. e BARROS, B.T. 1997. O estilo brasileiro de administrar: sumário de um modelo de ação cultural brasileiro com base na gestão empresarial. In: e CALDAS, M.P. (Orgs). Cultura organizacional e cultura brasileira. São Paulo, Atlas, p.55- 69.

ROCHA, A. e ROCHA, E. 1993. Controlling the future: a comparative analysis of U.S. and Brazilian insurance advertisements. Relatório COPPEAD. Rio de Janeiro. 271. 24 p.

ROCHA, A. 2000. Empresas e clientes: um ensaio sobre valores e relacionamentos no Brasil. São Paulo, Atlas, 216 p.

Schneider, S.C. 1988. National vs. corporate culture: implications for hum an resources management. Insead Working Papers Series, Fontainebleau, I NSEAD, 88 (4): $37 \mathrm{p}$.

1989. Strategy formulation: the impact of national culture. Organization Studies, 10(2): p.149- 168.

Stephens, K.G. e Geer, C.R. 1995. Doing business in Mexico: understanding cultural differences. Organizational Dynamics, 24(1): p.39- 54.

TANURE, B. 2005. Gestão à brasileira: uma comparação entre América Latina, Estados Unidos, Europa e Ásia. São Paulo, Atlas, 144 p.

TROMPENAARS, F. 1995. Riding.The Waves Of Culture: Understanding Cultural Diversity In Business. London, Nicholas Brealey Publishing, 198 p.

Ueno, S. e Sekaran, U. 1992. The influence of culture on budget control practices in the USA and Japan: an empirical study. Journal of International Business Studies, Fourth Quarter, p. 659-674.

Usunier, J.C.G. 1991. Business time perceptions and national cultures: a comparative survey. Management International Review, 31(3): p.197- 217.

WI LLMOTT, H. 1993. Strengh is ignorance; slavery is freedom: managing culture in modern organizations. Journal of Management Studies, 30 (4): p.515- 552.

Data de Submissão: 09/02/2007

Data de Aceite: 10/03/2007 